\title{
Different mutations at position 562 of the hepatitis $E$ virus capsid proteins exhibit differential effects on viral neutralizing activity
}

\author{
MINGJIE XU ${ }^{*}$, LIZHI SUN $^{1 *}$, YAN WANG $^{1}$, SHUCHUN GAO $^{2,3}$, WEIHUA YANG $^{1}$ and MENG LI ${ }^{1}$ \\ ${ }^{1}$ Medical Research and Laboratory Diagnostic Center, Jinan Central Hospital Affiliated to \\ Shandong First Medical University and Shandong Academy of Medical Sciences, Jinan, Shandong 250013; \\ ${ }^{2}$ Department of Liver Disease, Jinan Infectious Disease Hospital Affiliated to Shandong University; \\ ${ }^{3}$ Department of Digestive Disease, Shandong Provincial Hospital Affiliated to Shandong University, \\ Jinan, Shandong 250021, P.R. China
}

Received February 18, 2020; Accepted October 16, 2020

DOI: $10.3892 /$ etm.2020.9542

\begin{abstract}
The hepatitis E virus (HEV) capsid protein pORF2 comprises three potential N-linked glycosylation sites. One site, N562, is located at the cell attachment and neutralizing antigenic regions. The present study performed detailed analyses of the effects of specific amino acid substitutions at position 562 in the homodimerization, glycosylation, antigenicity, immunogenicity and neutralization activities of $\mathrm{HEV}$ pORF2. Recombinant HEV pORF2 glycoprotein E1 (amino acids 439-617) and three mutant variants (N562L, N562C and $\mathrm{N} 562 \mathrm{~K}$ ) were expressed in Pichia pastoris (P. pastoris) and SDS-PAGE, Western blot analysis, tunicamycin assay, double-antibody sandwich ELISA and in vitro PCR-based neutralization assay were performed to characterize the different constructs. All proteins were indicated to be secreted by $P$. pastoris and formed homodimers. Tunicamycin assay revealed the glycosylated status of the wild-type protein, but the mutants were indicated to be non-glycosylated. All proteins were immunoreactive with a neutralizing monoclonal antibody but were not recognized by the antibody after denaturation into monomers. An in vitro PCR-based neutralization assay using mouse antibodies indicated efficient neutralization against $\mathrm{N} 562 \mathrm{~L}$, whereas antibodies against $\mathrm{N} 562 \mathrm{C}$ and $\mathrm{N} 562 \mathrm{~K}$ were revealed to be non-neutralizing. Collectively, the present study indicated that specific amino acid substitutions
\end{abstract}

Correspondence to: Professor Meng Li, Medical Research and Laboratory Diagnostic Center, Jinan Central Hospital Affiliated to Shandong First Medical University and Shandong Academy of Medical Sciences, 105 Jiefang Road, Jinan, Shandong 250013, P.R. China

E-mail: 249260205@qq.com

*Contributed equally

Key words: hepatitis E virus, N562, glycosylation, dimerization, neutralization at position 562 serve crucial roles in the activity of the HEV neutralizing epitope.

\section{Introduction}

Hepatitis E virus (HEV) is an important causative agent of severe hepatitis in humans (1). However, it is a poorly understood pathogen, and has been indicated to cause high mortality during pregnancy (2) and result in chronic hepatitis in immunocompromised individuals, such as transplant recipients and HIV-infected patients with low CD4 cell counts $(3,4)$.

HEV belongs to the Orthohepevirus genus of the Hepeviridae family (5). The 7.2-kb HEV genome comprises three open reading frames (ORFs). ORF1 is a polyprotein required for HEV RNA replication, ORF2 is a capsid protein and ORF3 is a small phosphoprotein involved in virion morphogenesis and egress (6). ORF2 is involved in the formation of particle assembly, binding to host cells and elicitation of neutralizing antibodies (7-9). Its capsid protein comprises three domains: Domain S (amino acids 118-313) builds the viral shell, domain M (amino acids 314-453) contributes to a surface plateau at the 3 -fold axes of the virus capsid and domain $\mathrm{P}$ (amino acids 454-606) forms a protruding spike from the shell (10). It also includes a cell attachment region and neutralizing antigenic region (11).

In cultured cells and samples from infected patients, HEV produces three forms of the ORF2 protein: Intracellular, glycosylated and cleaved ORF2 (12). The ORF2 protein sequence comprises three potential positions for N-linked glycosylation: $\mathrm{N} 137$ and N310 in the S domain and N562 in the P domain (13). N562 is highly conserved and located at the apical center of the protruding spike, which comprises a cell attachment region and neutralizing antigenic region $(14,15)$. The location of N562 suggests that it may serve an important role in viral morphogenesis and immune responses; however, several wild strains contain an N562D mutation and it was reported that these strains successfully infected PLC/PRF/5 cells (16). Therefore, the biological functions of the other mutants at N562, and whether other types of amino acid mutations will stimulate the body to produce more efficient neutralizing antibodies, requires further elucidation. The effects of specific amino 
acid substitutions at N562 on the dimerization, antigenicity, immunogenicity and production of neutralizing antibodies in the $\mathrm{P}$ domain remain poorly understood. The present study performed site-directed mutagenesis on the truncated capsid protein HEV pORF2 E1 (amino acids 439-617) expressed in Pichia pastoris (P. pastoris) to investigate the effects of specific amino acid substitutions at N562 in the dimerization, antigenicity, immunogenicity and production of neutralizing antibodies in the $\mathrm{P}$ domain.

\section{Materials and methods}

Anti-HEV IgG assay. Serum samples were collected from 18 hospital patients with HEV (10 males and 8 females; age, 36-65 years), admitted to Jinan Central Hospital Affiliated to Shandong First Medical University and Shandong Academy of Medical Sciences (Jinan, China) between January and October 2019. Patients with psychiatric illness, malignancy, pregnancy, HIV infection, herpes zoster, bowel disease and celiac disease were excluded. All patients signed informed consent, and the study was approved by the Bioethics Committee of Jinan Central Hospital Affiliated to Shandong First Medical University and Shandong Academy of Medical Sciences. Serum samples were tested for anti-HEV IgG antibodies according to the manufacturer's protocol [HEV IgG antibody detection kit (Chemiluminescence microparticle immunoassay); cat. no. 20190904; Xiamen InnoDx. Biotech Co., Ltd.) using an automated chemiluminescent microparticle immunoassay system (Xiamen InnoDx Biotech Co., Ltd.). The result was considered positive when the signal-to-cut-off value of the sample was $>1.20$ (according to the manufacturer's recommendations). The anti-HEV IgG-positive human sera were subsequently pooled and stored at $-80^{\circ} \mathrm{C}$ until further use.

Homology modeling and in silico protein simulation. The SWISS-MODEL server accessible via the ExPASy website (http://swissmodel.expasy.org/) $(17,18)$ was used for homology modeling. This prediction server can use the known 3D protein structure with amino acid sequence homologous to the protein of interest and predict its 3D structure based on this homology, and automatically score the 3D protein structures. The best scoring models were used to simulate the pORF2 homodimer using the SymmDock server, which is an online server for the prediction of complexes with $\mathrm{C}_{\mathrm{n}}$ symmetry by geometry based docking (http://bioinfo3d.cs.tau.ac.il/SymmDock/), and the symmetry order used for docking was 2 (19).

Site-directed mutagenesis and construction of recombinant plasmids. Recombinant E1 encompassing residues 439-617 of genotype 4 HEV ORF2 was cloned into pET-28a (+) plasmid (Invitrogen; Thermo Fisher Scientific, Inc.), which has been previously constructed in the laboratory (20), and site-directed mutagenesis was performed to generate three mutant variants at N562. Amino acids with molecular weights similar to that of asparagine were selected (leucine, cysteine and lysine), representing aliphatic, sulfur-containing and alkaline amino acids, respectively. Regarding site-directed mutagenesis, the different E1 mutants were generated using the overlap PCR approach. The primers used for mutagenesis are listed in Table I, and PCR was performed using Expand High Fidelity PCR System
(Roche) as follows: Denaturation at $94^{\circ} \mathrm{C}$ for $45 \mathrm{sec}$, annealing at $54^{\circ} \mathrm{C}$ for $30 \mathrm{sec}$ and extension at $72^{\circ} \mathrm{C}$ for $60 \mathrm{sec}$ for a total of 35 cycles. The amplicons were separated by $1 \%$ agarose gel electrophoresis and visualized by ethidium bromide.

Expression of recombinant proteins in the P. pastoris strain SMD1168. The E1 gene and three mutants carried EcoRI and $X b a \mathrm{I}$ restriction sites at their $5^{\prime}$ and $3^{\prime}$ ends, respectively. All genes were cloned into EcoRI-XbaI-digested pPICZaA (Invitrogen; Thermo Fisher Scientific, Inc.). P. pastoris SMD1168 cells (Invitrogen; Thermo Fisher Scientific, Inc.) were cultured in $3 \mathrm{ml}$ Yeast Extract-Peptone-Dextrose (YPD) medium ( $1 \%$ yeast extract, $2 \%$ peptone, $2 \%$ dextrose) at $30^{\circ} \mathrm{C}$ and when the cells were in the log phase $(100 \mu \mathrm{l})$ they were mixed with $10 \mu \mathrm{g}$ plasmid linearized by $\mathrm{SacI}$ and were subsequently transferred to an electroporation cuvette and pulsed for $6 \mathrm{msec}$ at 1,000 V using BioRad Gene Pulser (Gene Pulser Xcell; Bio-Rad Laboratories, Inc.). In parallel, a control $P$. pastoris clone harboring the empty parent vector pPICZaA was generated. The transformation mixture $(200 \mu \mathrm{l})$ was plated in increasing concentrations of Zeocin ${ }^{\mathrm{TM}}$ (Invitrogen; Thermo Fisher Scientific, Inc.) to select putative multicopy recombinants at $30^{\circ} \mathrm{C}$ for 3 days.

A simple fed-batch protocol developed for high-level production of recombinant proteins by $P$. pastoris was used, as described previously (21). Briefly, recombinant clones were grown in $4 \mathrm{ml} \mathrm{YPD}$ medium at $30^{\circ} \mathrm{C}$ to an optical density $=1$ at $600 \mathrm{~nm}$ (OD600). Subsequently, $0.5 \mathrm{ml}$ of the cells were inoculated into $50 \mathrm{ml}$ buffered complex glycerol medium [ $1 \%$ yeast extract, $2 \%$ peptone, $100 \mathrm{mM}$ potassium phosphate $\mathrm{pH} 6.0,1.34 \%$ yeast nitrogen base (YNB), $4 \times 10^{-4} \%$ biotin, $1 \%$ glycerol] grown at $30^{\circ} \mathrm{C}$ until culture reached $\mathrm{OD} 600=20$. The cells were harvested by centrifugation at $1,500 \mathrm{x}$ g for $5 \mathrm{~min}$ at room temperature, washed with sterile double-distilled water, and resuspended in $10 \mathrm{ml}$ buffered methanol-complex medium (1\% yeast extract, $2 \%$ peptone, $100 \mathrm{mM}$ potassium phosphate pH 6.0, $1.34 \%$ YNB, $4 \times 10^{-4} \%$ biotin, $0.5 \%$ methanol). The expression of recombinant proteins was induced for $72 \mathrm{~h}$ at $30^{\circ} \mathrm{C}$, with $100 \%$ methanol being added to a final concentration of $0.5 \%$ every $12 \mathrm{~h}$ to maintain the promoter activity. After induction for $72 \mathrm{~h}$, the cells were harvested by centrifugation at $13,800 \mathrm{x}$ g for $20 \mathrm{~min}$ at room temperature. Both the cells and supernatant were stored at $-80^{\circ} \mathrm{C}$.

SDS-PAGE and western blotting. A total of $20 \mu 1$ from $10 \mathrm{ml}$ culture supernatant was mixed with $4 \mu \mathrm{l}$ 6x SDS-PAGE loading buffer, boiled $\left(100^{\circ} \mathrm{C}\right)$ for $5 \mathrm{~min}$, analyzed on $15 \%$ SDS-PAGE and stained with Coomassie blue. For non-reducing SDS-PAGE, the buffer did not contain $\beta$-mercaptoethanol and the samples were analyzed without boiling. For western blot analysis, the separated proteins were electrotransferred onto a nitrocellulose membrane. The membrane was incubated for $1 \mathrm{~h}$ at room temperature with blocking buffer (5\% nonfat milk power in $0.05 \%$ Tween-20-TBS]. The monoclonal antibody $(\mathrm{mAb}) 5 \mathrm{G} 5$, which was produced in our laboratory, and anti-HEV IgG-positive human sera were used as primary antibodies (1:200) incubated at $4^{\circ} \mathrm{C}$ overnight. HRP-conjugated goat anti-mouse (cat. no. 5220-0287) and anti-human IgG (cat. no. 5220-0277; both from KPL) were used as secondary antibodies $(1: 2,000)$ for $2 \mathrm{~h}$ at room temperature. Color 
Table I. Primers used for mutagenesis.

\begin{tabular}{ll}
\hline Construct & Sequence $\left(5^{\prime}-3^{\prime}\right)$ \\
\hline E1N562 & F: CCC GAA TTC GTT ATC CAG GAC TAT GAT AAT C \\
& R: TCT TCT AGA TCA AGG GTA ATC AAC AGT GTC C \\
E1N562L & F: ATC ACT AGC AGT AGT TTG ATA ATT GTA TGG G \\
& R: CCA TAC AAT TAT ttg ACT ACT GCT AGT GAT C \\
E1N562C & F: ATC ACT AGC AGT AGT ATC ATA ATT GTA TGG G \\
& R: TAC CCA TAC AAT TAT tgt ACT ACT GCT AGT G \\
E1N562K & F: ATC ACT AGC AGT AGT TGG ATA ATT GTA TGG G \\
& R: TAC CCA TAC AAT TAT aag ACT ACT GCT AGT G
\end{tabular}

The restriction sites introduced in the primer sequences are underlined. Lowercase letters indicate modified codons in the ORF2 protein. F, forward; R, reverse.

development was performed with 3,3'-diaminobenzidin tetrahydrochloride (MilliporeSigma; Merck KGaA) as a substrate for HRP.

Tunicamycin assays. For the detection of protein glycosylation, the $P$. pastoris SMD1168 cells were divided into two equal aliquots during induction periods: One aliquot was supplemented with tunicamycin, which was dissolved in $1 \%$ (v/v) DMSO at a final concentration of $50 \mu \mathrm{g} / \mathrm{ml}$ according to Ito et al (22), whereas the other aliquot was incubated without tunicamycin. The culture supernatants were harvested after 3 days of induction and subjected to SDS-PAGE analysis, which was the same protocol reported in the previous paragraph.

Double-antibody sandwich ELISA. Double-antibody sandwich ELISA was performed to compare the antigenicity of the four recombinant $\mathrm{HEV}$ capsid proteins at the same concentration. Microtiter plates were coated with mAb 4E9 [100 $\mu \mathrm{l} /$ well, 1:200 dilution in CBS buffer ( $\mathrm{pH} 9.6 ; 0.05 \mathrm{M} ; 1.59 \mathrm{~g} \mathrm{Na}_{2} \mathrm{CO}_{3}$ and $2.93 \mathrm{~g} \mathrm{NaHCO}_{3}$ up to $1,000 \mathrm{ml}$ double-distilled water) at $37^{\circ} \mathrm{C}$ for $2 \mathrm{~h}$. The proteins were serially diluted from 1:100 to $1: 51,200$ and incubated at $37^{\circ} \mathrm{C}$ for $45 \mathrm{~min}$. After incubation with HRP-5G5 $(1: 5,000)$ at $37^{\circ} \mathrm{C}$ for $45 \mathrm{~min}$, the reaction was developed using $100 \mu \mathrm{l}$ tetramethylbenzidine (MilliporeSigma; Merck KGaA) at $37^{\circ} \mathrm{C}$ for $10 \mathrm{~min}$ and stopped using $50 \mu \mathrm{l}$ $2 \mathrm{M} \mathrm{H}_{2} \mathrm{SO}_{4}$. Optical density was measured at $450 \mathrm{~nm}$. The empty vector pPICZaA produced from SMD1168 was used as a negative control. The mAb 4E9 used in the present study was a gift from Changchun Institute of Biological Products Co., Ltd. The HRP-5G5 antibody was previously produced in our laboratory.

Immunization schedule and anti-HEV antibody detection. Each protein was emulsified with Freund's complete adjuvant (MilliporeSigma; Merck KGaA) and was used to immunize a group of six specific pathogen-free female BALB/c mice at 6 weeks of age with 20-25 g weight (obtained from the Animal Resource Centre of Yangzhou University, Yangzhou, China). During the animal experiment, the mice were maintained at $20-26^{\circ} \mathrm{C}, 40-70 \%$ relative humidity with a $12 / 12$-h light/dark cycle and had free access to autoclaved food pellets and autoclaved water, The mice were subcutaneously inoculated at two locations on the back with $20 \mu \mathrm{g}$ of the target protein, quantified using the Bradford method. After 3 and 5 weeks, the mice were administered an intraperitoneal booster injection with $20 \mu \mathrm{g}$ of the target protein without the adjuvant. Blood samples (200 $\mu \mathrm{l})$ were collected from the ocular venous plexus of each mouse at $0,3,5,8,10,12,14,16,18,20,22,24,26,28,30,32$, 34,36 and 38 weeks. The ocular venous plexus was selected to collect blood from the mice, as this method was indicated to cause only minimal injury to the animals and is easy to perform. Prior to blood collection, the mice were anesthetized by an intraperitoneal injection of $400 \mathrm{mg} / \mathrm{kg}$ chloral hydrate. The immune serum samples obtained from each group of mice were pooled. At the end of the animal experiment, the mice were euthanized by $\mathrm{CO}_{2}$ inhalation $(60 \% ; 31 / \mathrm{min})$ in a 10 -liter volume euthanasia chamber (23). After the animals gradually lost consciousness, $\mathrm{CO}_{2}$ concentration was increased to $100 \%$ and maintained for $>10$ min to ensure the animals' death. At that time, the animals did not breathe spontaneously for 2-3 min without blinking reflex. The animals died entirely unconscious. All procedures involving animals were approved and performed according to the guidelines for animal experimentation of the Jinan Central Hospital Affiliated to Shandong First Medical University and Shandong Academy of Medical Sciences Ethics Service Committee (Jinan, China). Anti-HEV IgG antibodies in mouse sera were detected by indirect ELISA, as described previously (24). Briefly, microtiter plates were coated with $100 \mu \mathrm{l} /$ well of p166 mix [previously produced in our laboratory; four p166 recombinant proteins (amino acids 452-617 of HEV) were generated from W1 (genotype 1; JX857689), Mexico-14 (genotype 2; M74506), US-1 (genotype 3; AF060668) and China-9829 (genotype 4; AY789225) and mixed in equal concentrations] in $1 \mathrm{M}$ urea in PBS at a concentration of $1 \mu \mathrm{g} / \mathrm{ml}(24)$. The plates were incubated at $37^{\circ} \mathrm{C}$ for $2 \mathrm{~h}$. A total of $100 \mu \mathrm{l}\left(1 \times 10^{4}\right.$ dilution) of immune sera in $10 \%$ ethylene glycol were added to each well, and subsequently incubated for $45 \mathrm{~min}$ at $37^{\circ} \mathrm{C}$, followed by incubation with an HRP-conjugated goat anti-mouse IgG (cat. no. 5220-0287, 1:5,000; KPL USA). The reaction was developed using $100 \mu 13,3^{\prime}, 5,5^{\prime}$-tetramethylbenzidine at $37^{\circ} \mathrm{C}$ for $10 \mathrm{~min}$ (MilliporeSigma), and then terminated using $50 \mu \mathrm{l}$ $2 \mathrm{M} \mathrm{H}_{2} \mathrm{SO}_{4}$. The optical density was measured at $450 \mathrm{~nm}$ with a reference wavelength of $630 \mathrm{~nm}$. 
In vitro PCR-based neutralization assay. The titers of the neutralizing antibodies were tested by an in vitro PCR-based neutralization assay $(25,26)$. The inactivated $\left(60^{\circ} \mathrm{C}\right.$ for $\left.30 \mathrm{~min}\right)$ serum samples were serially diluted from $1: 10$ to $1: 80$ by two-fold steps using Hanks' Balanced Salt solution (HBSS). The NJ703 HEV genotype 4 strain (GenBank accession no. AY789228; isolated from the stool of an acute HEV-infected patient in our laboratory) was diluted at 1:500 using HBSS and was mixed with equal volumes $(100 \mu \mathrm{l})$ of the diluted serum. The mixture was incubated at $37^{\circ} \mathrm{C}$ for $1 \mathrm{~h}$ and inoculated onto an A549 cell monolayer (cat. no. CCL-185; American Type Culture Collection) in DMEM medium supplemented with $10 \%$ FBS (Invitrogen; Thermo Fisher Scientific, Inc.). After incubation for 5 days at $37^{\circ} \mathrm{C}$ in $5 \% \mathrm{CO}_{2}$, the cells were washed three times with HBSS, followed by immediate RNA extraction using TRIzol ${ }^{\circledR}$ reagent (Invitrogen; Thermo Fisher Scientific, Inc.). One-step reverse transcription (RT) PCR was conducted, as described previously (21). OneStep RT-PCR kit (Qiagen $\mathrm{GmbH}$ ) and universal HEV PCR primers, forward, 5'-CCGACAGAATTGATTTCGTCGGC-3; and reverse, 5'-TCGGCGGCGGTGAGAGAGAGCCA-3', were used as follows: RT, $50^{\circ} \mathrm{C}$ for $45 \mathrm{~min}$ and $95^{\circ} \mathrm{C}$ for $15 \mathrm{~min}$; PCR, denaturation at $94^{\circ} \mathrm{C}$ for $30 \mathrm{sec}$, annealing at $62^{\circ} \mathrm{C}$ for $30 \mathrm{sec}$ and extension at $72^{\circ} \mathrm{C}$ for $45 \mathrm{sec}$ for 55 cycles. The amplicons were separated by $1 \%$ agarose gel electrophoresis and visualized using ethidium bromide. Neutralization was defined by the absence of detectable HEV RNA in the inoculated cell culture.

Statistical analysis. The double-antibody sandwich ELISA was repeated twice and the results are presented as the mean \pm SD. Differences in the immunoreactivity with mAb 4E9 between wild-type (WT) E1 and its three mutant groups were examined by one-way ANOVA followed by Tukey's post hoc test. SPSS v20.0 (IBM Corp.) was used for statistical analysis and the results were graphically illustrated using GraphPad Prism v5.0 (GraphPad Software, Inc.). $\mathrm{P}<0.05$ was considered to indicate a statistically significant difference.

\section{Results}

Predicted secondary structure models and in silico simulations of homodimerization. The WT protein and its mutants exhibited similar secondary structures, with the WT and the three mutated residues all located on the coils (Fig. 1A). The best ranked 3D models were selected among the available E1 protein structures using the SWISS-MODEL server. Subsequently, dimerization was simulated using the SymmDock server. The best simulations (the molecular simulations closest to the spatial structure of the target protein) indicated that N562 was engaged in the formation of homodimers, which is the case in the proposed quaternary structure of the HEV-like particle (Protein Data Bank ID: 2ZTN). To evaluate the engagement of N562 in the four predicted E1 homodimers, (E1)2, (E1 N562L)2, (E1 N562C)2 and (E1 N562K)2, the distance between two monomers at N562 was measured and compared with those in the $2 \mathrm{ZTN}$ model (Fig. 1B). The distances between N562 and N562 (the same position in the second monomer) was $20.9 \AA$ in the $2 \mathrm{ZTN}$ model. This distance allows N562 to engage in hydrogen bonding with the neighboring amino acids in the opposite monomer and participate in the assembly of the two monomers. Accordingly, concerning (E1 N562L)2, the distance between L562 and L562' was 43.1 $\AA$, which was closer to the distance measured in the $2 \mathrm{ZTN}$ model compared with that in the WT, E1 N562C and E1 N562K, which were predicted to exhibit distances of $53.3,55.8$ and $73.4 \AA$ A, respectively. This indicated that the amino acid at position 562 was better positioned to engage in homodimerization in the N562L model compared with the WT, N562C and N562K models.

Protein dimerization. Non-reducing SDS-PAGE was performed to verify the dimerization of E1 N562L, E1 N562C and E1 N562K mutants compared with that of the WT protein. E1 N562L, E1 N562C and E1 N562K were assembled into 39-kDa homodimers (Fig. 2; lanes 3, 5 and 7), whereas the WT protein was assembled into a $44-\mathrm{kDa}$ homodimer (Fig. 2; lane 1). Analysis of the denatured proteins indicated that the E1 N562L, E1 N562C and E1 N562K mutant proteins were 19-kDa in size (Fig. 2; lanes 4, 6 and 8), whereas WT E1 migrated as a 21-kDa protein on the gel (Fig. 2; lane 2). Proteins from pPICZaA/SMD1168 were used as negative control.

WT protein is a glycoprotein, but its mutants are not glycosylated. The observation of a higher molecular weight of the WT protein suggested that it may be glycosylated, whereas the mutant proteins were either non-glycosylated or a relatively smaller fraction was glycosylated. Tunicamycin, which is an inhibitor of bacterial and eukaryote $\mathrm{N}$-acetylglucosamine transferases, is known to prevent the glycosylation of newly synthesized glycoproteins (27). Therefore, tunicamycin assays were performed to evaluate the glycosylation status of the WT protein and its mutants. In the presence of tunicamycin, the glycosylation of the WT protein was inhibited, leading to a shift from the higher molecular weight to the lower molecular eight form (Fig. 3; lanes 1 and 2). The WT protein was validated to be a glycoprotein, as it was susceptible to tunicamycin treatment. However, the electrophoretic mobility of the three mutants was unaffected by tunicamycin treatment, suggesting that the mutants were not glycosylated (Fig. 3; lanes 3 to 8).

Immunoreactivity of the WT protein and its three mutants. Western blot analysis demonstrated that the WT protein and N562L, N562C and N562K immunoreacted with the HEV-neutralizing mAb $5 \mathrm{G} 5$ as homodimers but were not reactive as monomers (Fig. 4A). Western blot analysis was also performed using anti-HEV IgG-positive human sera, and the results were indicated to be similar to those obtained with mAb 5G5 (Fig. 4B). Proteins from pPICZaA/SMD1168 were used as negative control.

Antigenicity. The antigenicity of the expressed proteins was assessed using double-antibody sandwich ELISAs. The immunoreactivity levels were indicated to be decreased as the dilution increased. The immunoreactivity of WT E1 was significantly lower compared with that of the three mutant variants (Fig. 5A; P<0.05). Moreover, pPICZaA/SMD1168 exhibited no reactivity to $\mathrm{mAb} 4 \mathrm{E} 9$. These results indicated that a sugar chain at N562 may mask the partially neutralizing 
A

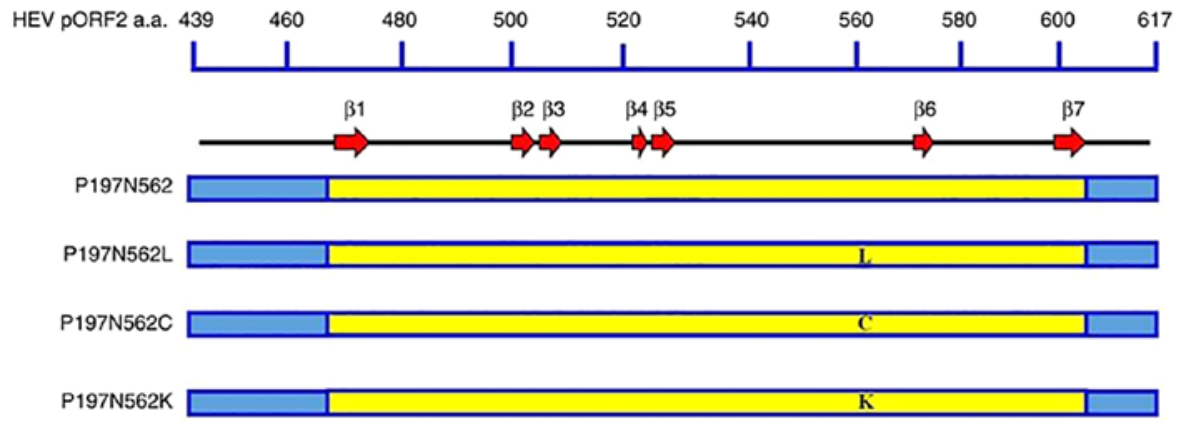

B
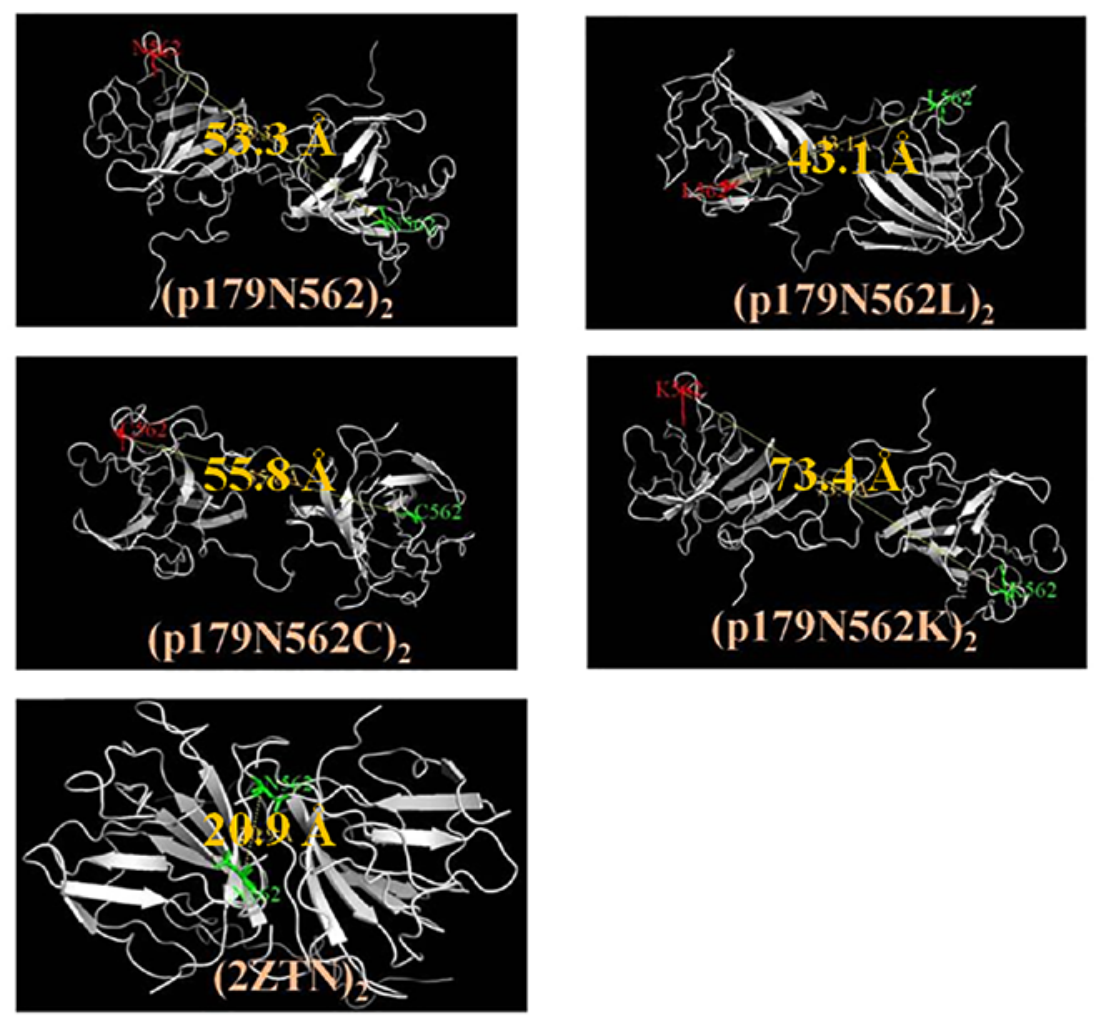

Figure 1. Mutational studies on the dimer interface. (A) Schematic representation of wild-type E1 and three-point mutations targeting the dimer interface region. Secondary structural elements are presented for the E1 region. The mutated residues were located on the coils, and $\beta$-strands and coils are indicated in red and black, respectively. (B) Distances between the two aa 562 in each monomer measured on the (2ZTN)2 model and the predicted homodimers (E1N562)2, (E1N562L)2, (E1N562C)2 and (E1N562K)2. aa, amino acid; HEV, hepatitis E virus.

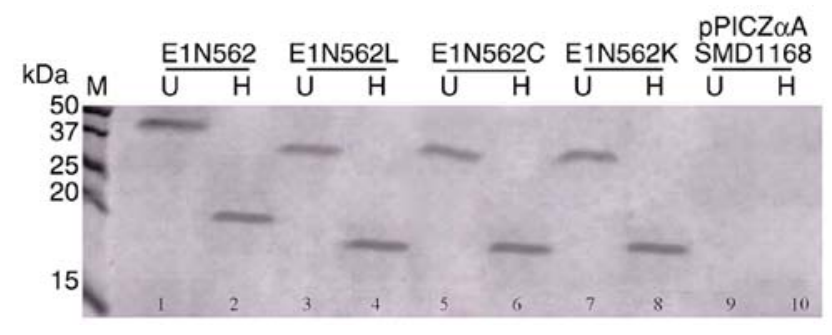

Figure 2. Western blot analysis of the indicated expressed proteins. $\mathrm{U}$, unheated; $\mathrm{H}$, heated; $\mathrm{M}$, molecular weight marker.

epitopes, thereby reducing the reactivity with the neutralizing $\mathrm{mAb}$.

Immunoreactivity. All mice vaccinated with the recombinant proteins presented HEV-specific antibodies in sera at 3 weeks

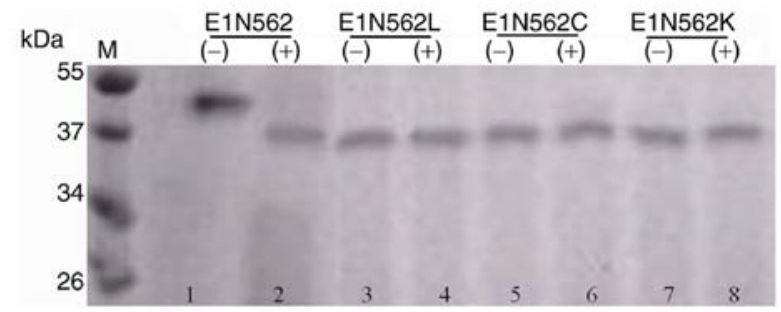

Figure 3. Effect of tunicamycin on the expression of the indicated glycoproteins at non-denaturing conditions. (-), untreated protein; (+), treated protein; $\mathrm{M}$, molecular weight marker.

post inoculation (wpi). The E1-, E1 N562L-, E1 N562C- and E1 N562K-vaccinated mice exhibited peak levels of antibody titers at 10 wpi. Overall, the kinetics of antibody responses were highly similar among the four groups, indicating that the amino acid substitutions and glycosylation status resulted 


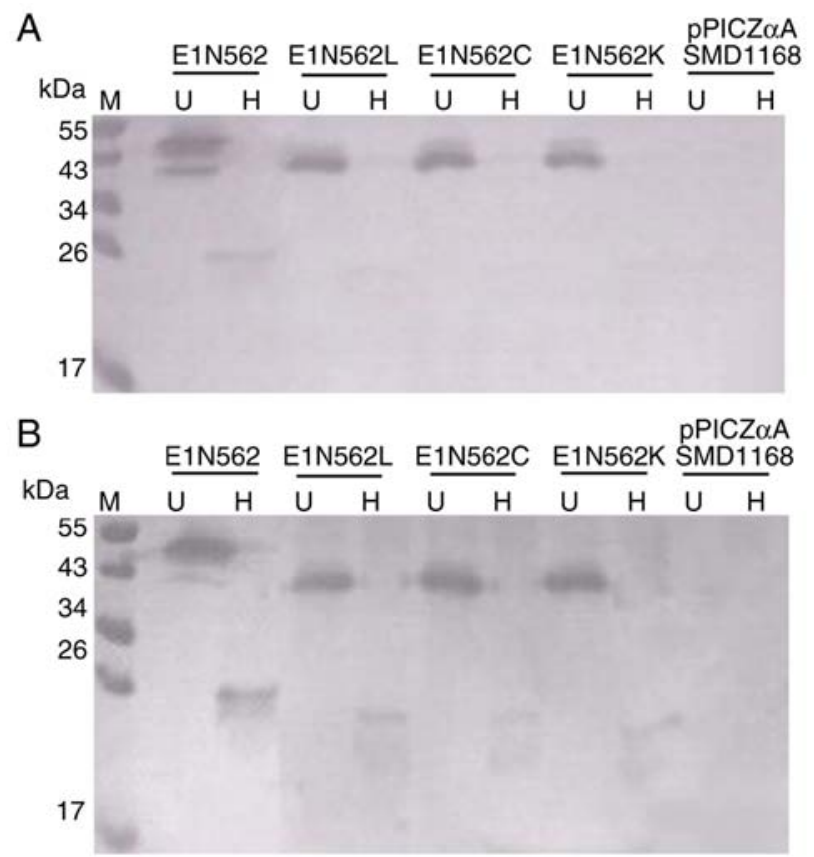

Figure 4. Immunoreactivity of E1N562 and its mutants with (A) mAb 5G5 and (B) anti-hepatitis E virus IgG-positive human sera detected by western blotting. $\mathrm{U}$, unheated; $\mathrm{H}$, heated; $\mathrm{M}$, molecular weight marker.

in no significant differences in their kinetics. All immunized mice retained the $1 \times 10^{4}$ dilution of immune sera until 38 wpi (Fig. 5B).

Neutralization activity of mouse sera. The ability of immune sera to neutralize HEV was determined by an in vitro PCR-based neutralization assay. Four pools of the E1, E1 N562L, E1 N562C and E1 N562K serum samples were prepared from 8 wpi. Pre-inoculation serum specimens were used as negative controls. The endpoint neutralization titers of the antibodies against E1 and E1 N562L were 1:20 and 1:80, respectively (Fig. 6). No neutralization was observed using E1 N562C, E1 N562K and pre-inoculation sera diluted 1:10.

\section{Discussion}

The HEV capsid protein encoded by ORF2 is responsible for the formation of particle assembly, binding to host cells and elicitation of neutralizing antibodies $(28,29)$. Considerable effort has been made for the expression of recombinant ORF2 protein to create a subunit vaccine (30-32). In the present study, a secretory truncated version of the ORF2 protein was successfully expressed using $P$. pastoris as a host system. Gurramkonda et al (33) previously reported a simple two-phase strategy. In the first phase, they used a glycerol batch phase to generate sufficient biomass. In the second phase, they used methanol induction at a constant methanol concentration to achieve high-level production of the recombinant protein. In the present study, this two-phase strategy was successfully employed for the secretion of E1. The addition of methanol once every $12 \mathrm{~h}$ is recommended to prevent methanol depletion, as performed in the present study.
The potential glycosylation motif ${ }^{562} \mathrm{NTT}$ has been indicated to be highly conserved, and only six out of 261 sequences (GenBank accession nos. AB189070, AB425831, AB593690, AB698071, AB740232 and JQ026407) (34-37) have been revealed to comprise D562, which is incompatible with the $\mathrm{N}$-linked glycosylation at this position. N562 is located in the central region at the top of the P dimer and is exposed on the surface of HEV (13). Owing to its location in functionally and structurally important regions of the HEV capsid protein, this position possibly serves a crucial role in viral immune responses and morphogenesis (38). In the present study, a set of mutant proteins containing $\mathrm{L}, \mathrm{C}$ and $\mathrm{K}$ in place of $\mathrm{N}$ at position 562 was constructed and tested for homodimerization, glycosylation, antigenicity, immunogenicity and neutralization activity.

In the current study, E1 was indicated to form a $44-\mathrm{kDa}$ homodimer. This molecular weight is slightly higher compared with the predicted molecular weight of $40 \mathrm{kDa}$ based on the 179-amino acid sequence. The slightly higher molecular weight resulted from a facultative $\mathrm{N}$-linked glycosylation site $(\mathrm{N}-\mathrm{X}-\mathrm{S} / \mathrm{T})$ at $\mathrm{N} 562$ of the $\mathrm{P}$ domain. Tunicamycin is an inhibitor of bacterial and eukaryotic $\mathrm{N}$-acetylglucosamine transferases, preventing the formation of $\mathrm{N}$-acetylglucosamine lipid intermediates and the glycosylation of newly synthesized glycoproteins (27). Tunicamycin has been indicated to block the formation of $\mathrm{N}$-glycosidic linkages by inhibiting the transfer of $\mathrm{N}$-acetylglucosamine-1-phosphate to dolichol monophosphate (27). Tunicamycin assay revealed that the 44-kDa protein homodimer was glycosylated. The N562L, N562C and N562K mutations completely abrogated the glycosylation, thereby supporting the importance of the asparagine residue for glycosylation at this position, as reported previously (39).

Li et al (38) reported that the dimerization of the capsid E2s domain (ORF2; amino acids 455-602) was a prerequisite for the virus-host interaction and for the binding of certain neutralizing antibodies to HEV. The findings of the present study indicated that E1 WT, E1 N562L, E1 N562C and E1 N562K formed a homodimer, suggesting that replacing N562 with leucine, cysteine or lysine exhibited no effect on dimerization. It may be possible that the $P$. pastoris expression-secretion system used in the current study was conducive to the formation of homodimers.

E1, E1 N562L, E1 N562C and E1 N562K were revealed to interact with mAb 5G5 and anti-HEV IgG-positive human sera as homodimers, whereas their denaturation abrogated this immunoreactivity.

Furthermore, determination of immune response rates and antibody neutralization capacities demonstrated that all four recombinant HEV capsid proteins elicited similar antibody responses in immunized mice, but not all antibodies were neutralized in the in vitro PCR-based neutralization assay. The observation that E1 N562L elicited the strongest neutralizing antibody response among the tested proteins suggested that specific amino acid substitutions at position 562 resulted in differential effects on the immunological properties and neutralization of these proteins. However, additional experiments are required to support these results. A comparison experiment between E1 N562L and E1 N562 should be performed by measuring neutralizing antibody 

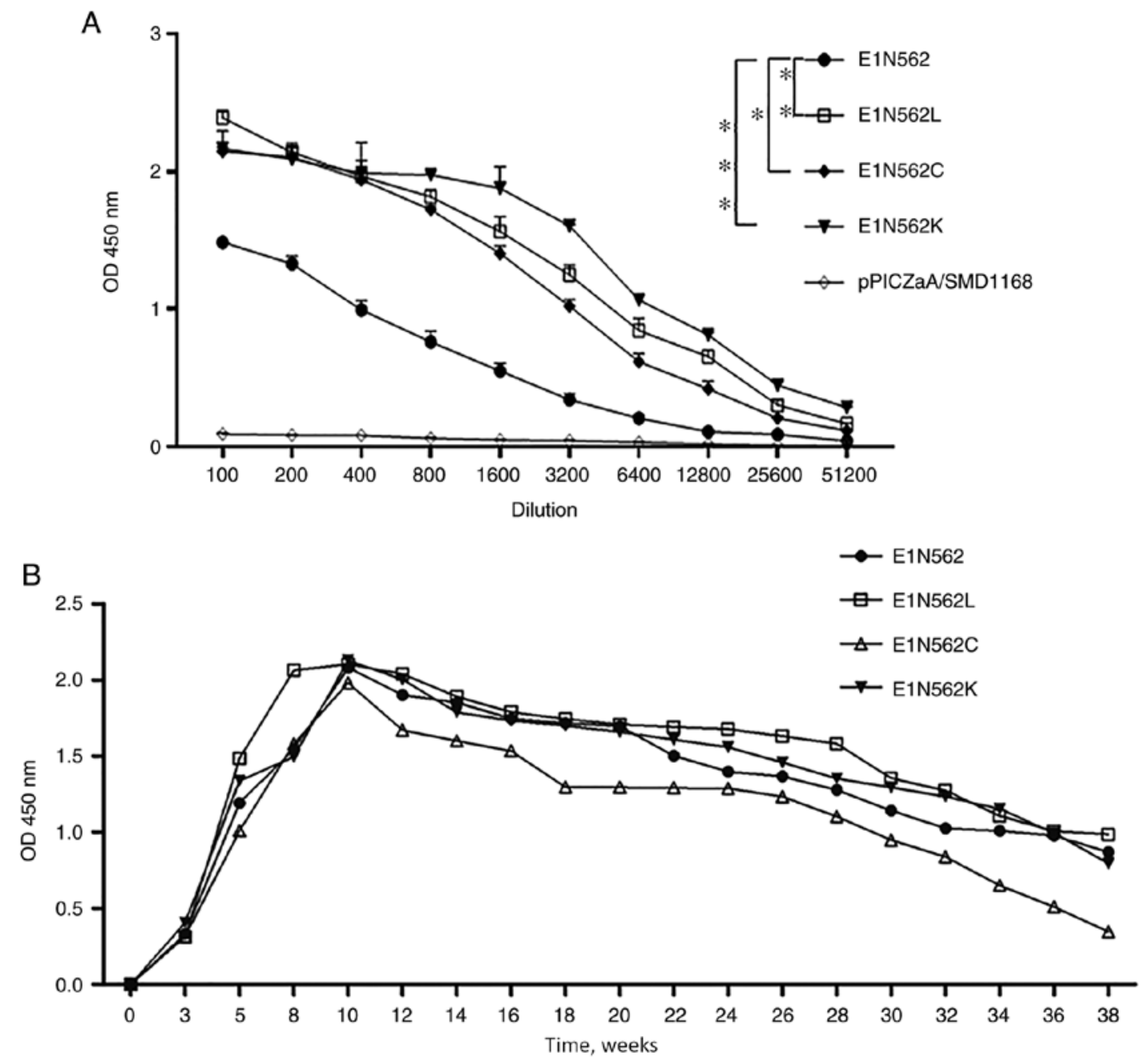

Figure 5. Immunoreactivity and antigenicity of the wild-type protein and its three mutants. (A) Immunoreactivity of E1N562, E1N562L, E1N562C and E1N562K with mAb 4E9 in double-antibody sandwich ELISA. Data are presented as the mean $\pm \mathrm{SD}$. ${ }^{*} \mathrm{P}<0.05 ;{ }^{* * *} \mathrm{P}<0.01 ;{ }^{* * * *} \mathrm{P}<0.001$ at the 1:100-1:12,800 dilution (B) Temporal hepatitis E virus-specific antibody responses induced by E1N562, E1N562L, E1N562C and E1N562K in BALB/c mice. The antigen-specific-IgG responses were measured by indirect ELISA. Optical density values are presented as the average of 6 mice/group.

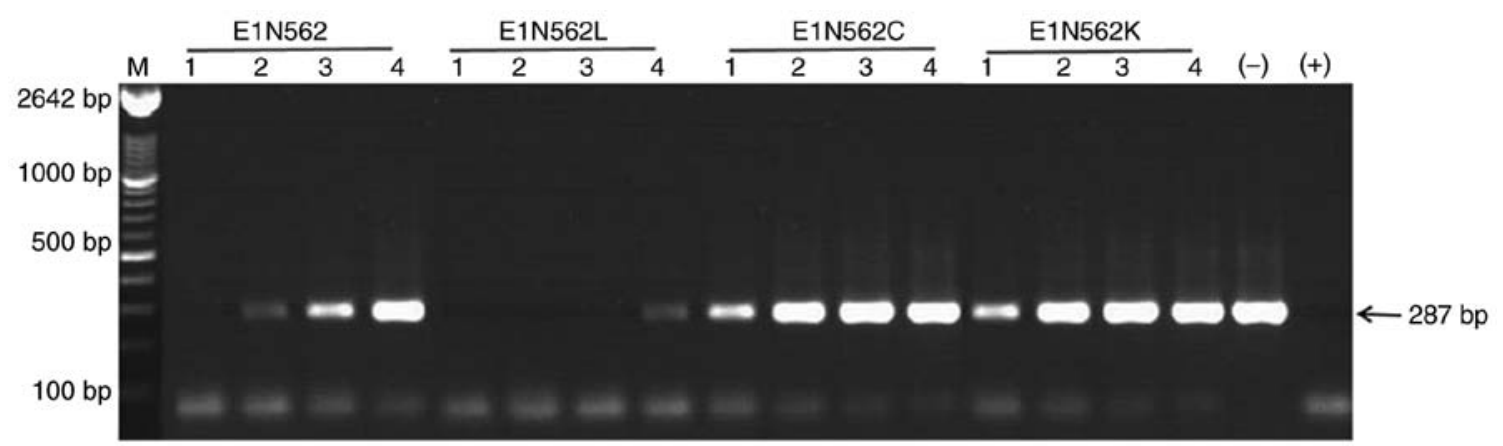

Figure 6. HEV neutralization detected using an in vitro PCR-based neutralization assay. The NJ703 HEV genotype 4 strain was incubated with serial dilutions of sera obtained against E1 protein and its mutants prior to inoculation to the A549 cell culture. Neutralization was determined by the absence of detectable HEV RNA (287 bp) in the inoculated cell culture for 5 days. Lanes 1 to 4 correspond to serial dilutions of the sera from 1:10 to 1:80 by two-fold steps, respectively. (+) indicates the positive control (HEV was incubated with a known HEV neutralizing serum diluted 1:10) and (-) indicates the negative control (HEV was incubated with the pre-inoculation sera at 1:10 dilution). M, DNA molecular weight marker; HEV, hepatitis E virus.

levels at different doses of E1 N562L and E1 N562, such as 5,10 and $20 \mu \mathrm{g}$, to further support these conclusions.

In conclusion, analyses of the four recombinant HEV capsid proteins comprising different mutations at position 562 revealed differential effects of mutations at this position on the neutralizing capacity of the examined antibody. This finding contributed to a greater understanding of the antigenic characteristics of the glycosylated and non-glycosylated form of capsid protein ORF2 and may be helpful in the development of novel vaccines and diagnostic methods. 


\section{Acknowledgements}

The authors would like to thank Dr Duanrui Liu (Shandong University) for providing human clinical samples collected from patients and Dr Kangle Niu (Shandong University) for their valuable technical assistance and suggestions.

\section{Funding}

The present study was funded by the Academic Promotion Program of Shandong First Medical University (grant no. 2019QL024), Natural Science Foundation of Shandong Province (grant no. ZR2017BC002), Jinan Clinical Medicine Science and Technology Innovation Plan (grant no. 201704117) and Jinan Postdoctoral Innovation Project Second-Class Funding (grant no. 197249).

\section{Availability of data and materials}

All data generated or analyzed during the present study are included in this published article.

\section{Authors' contributions}

MX performed site-directed mutagenesis and was a major contributor in writing the manuscript. LS detected and analyzed the patient with HEV for anti-HEV IgG antibody in the patient's serum, performed expression of recombinant proteins in the $P$. pastoris strain SMD1168. YW performed SDS-PAGE and western blotting. SG performed the immunization schedule and anti-HEV antibody detection. WY performed for the purification of proteins. ML designed the research, performed in vitro $\mathrm{PCR}$-based neutralization assay and statistical analysis. All authors read and approved the final manuscript.

\section{Ethics approval and consent to participate}

All patients signed an informed consent, and the study was approved by the Bioethics Committee of Jinan Central Hospital Affiliated to Shandong First Medical University and Shandong Academy of Medical Sciences (Jinan, China). All procedures involving animals were approved and performed according to the guidelines for animal experimentation of the Jinan Central Hospital Affiliated to Shandong First Medical University and Shandong Academy of Medical Sciences Ethics Service Committee (Jinan, China).

\section{Patient consent for publication}

Not applicable.

\section{Competing interests}

The authors declare that they have no competing interests.

\section{References}

1. Yamada H, Takahashi K, Lim O, Svay S, Chuon C, Hok S, Do SH, Fujimoto M, Akita T, Goto N, et al: Hepatitis E Virus in Cambodia: Prevalence among the general population and complete genome sequence of genotype 4. PLoS One 10: e0136903, 2015.
2. Pérez-Gracia MT, Suay-García B and Mateos-Lindemann ML: Hepatitis E and pregnancy: Current state. Rev Med Virol 27: e1929, 2017.

3. Abravanel F, Lhomme S, Fougère $M$, Saune K, Alvarez M, Péron JM, Delobel P and Izopet J: HEV infection in French HIV-infected patients. J Infect 74: 310-313, 2017.

4. Debes JD, Pas SD, Groothuismink ZMA, van der Ende ME, de Man RA and Boonstra A: A mutation in the progesterone receptor predisposes to $\mathrm{HEV}$ infection in $\mathrm{HIV}$-positive patients. Liver Int 38: 792-796, 2018.

5. Kasem A, Izopet J, Pavio N, Aggarwal R, Labrique A, Wedemeyer $\mathrm{H}$ and Dalton HR: Epidemiology of hepatitis $\mathrm{E}$ virus infection. Epidemiol Mikrobiol Imunol 68: 176-182, 2019.

6. Tam AW, Smith MM, Guerra ME, Huang CC, Bradley DW, Fry KE and Reyes GR: Hepatitis E virus (HEV): Molecular cloning and sequencing of the full-length viral genome. Virology 185: 120-131, 1991.

7. Li S, Zhang $\mathrm{J}$ and Xia $\mathrm{N}$ : Lessons from hepatitis $\mathrm{E}$ vaccine design. Curr Opin Virol 11: 130-136, 2015.

8. Chandra V, Kalia M, Hajela K and Jameel S: The ORF3 protein of hepatitis $\mathrm{E}$ virus delays degradation of activated groWTh factor receptors by interacting with CIN85 and blocking formation of the Cbl-CIN85 complex. J Virol 84: 3857-3867, 2010.

9. Takahashi M, Yamada K, Hoshino Y, Takahashi H, Ichiyama K, Tanaka $\mathrm{T}$ and Okamoto $\mathrm{H}$ : Monoclonal antibodies raised against the ORF3 protein of hepatitis E virus (HEV) can capture HEV particles in culture supernatant and serum but not those in feces. Arch Virol 153: 1703-1773, 2008.

10. Guu TS, Liu Z, Ye Q, Mata DA, Li K, Yin C, Zhang J and Tao YJ: Structure of the hepatitis E virus-like particle suggests mechanisms for virus assembly and receptor binding. Proc Natl Acad Sci USA 106: 12992-12997, 2009.

11. Yamashita T, Mori Y, Miyazaki N, Cheng RH, Yoshimura M, Unno H, Shima R, Moriishi K, Tsukihara T, Li TC, et al: Biological and immunological characteristics of hepatitis $\mathrm{E}$ virus-like particles based on the crystal structure. Proc Natl Acad Sci USA 106: 12986-12991, 2009.

12. Yin X, Ying D, Lhomme S, Tang Z, Walker CM, Xia N, Zheng Z and Feng Z: Origin, antigenicity, and function of a secreted form of ORF2 in hepatitis E virus infection. Proc Natl Acad Sci USA 115: 4773-4778, 2018.

13. Zafrullah M, Ozdener MH, Kumar R, Panda SK and Jameel S: Mutational analysis of glycosylation, membrane translocation, and cell surface expression of the hepatitis E virus ORF2 protein. J Virol 73: 4074-4082, 1999.

14. Mori Y and Matsuura Y: Structure of hepatitis E viral particle. Virus Res 161: 59-64, 2011.

15. Graff J, Zhou YH, Torian U, Nguyen H, St Claire M, Yu C, Purcell RH and Emerson SU: Mutations within potential glycosylation sites in the capsid protein of hepatitis E virus prevent the formation of infectious virus particles. J Virol 82: 1185-1194, 2008.

16. Shiota T, Li TC, Yoshizaki S, Kato T, Wakita T and Ishii K: The hepatitis E virus capsid C-terminal region is essential for the viral life cycle: Implication for viral genome encapsidation and particle stabilization. J Virol 87: 6031-6036, 2013.

17. Biasini M, Bienert S, Waterhouse A, Arnold K, Studer G, Schmidt T, Kiefer F, Gallo Cassarino T, Bertoni M, Bordoli L and Schwede T: SWISS-MODEL: Modelling protein tertiary and quaternary structure using evolutionary information. Nucleic Acids Res 42: W252-W258, 2014.

18. Arnold K, Bordoli L,Kopp J and Schwede T: The SWISS-MODEL workspace: A web-based environment for protein structure homology modelling. Bioinformatics 22: 195-201, 2006.

19. Zhang C, Vasmatzis G, Cornette JL and DeLisi C: Determination of atomic desolvation energies from the structures of crystallized proteins. J Mol Biol 267: 707-726, 1997.

20. Chen D and Meng J: Expression, purification and immunogenicity of a novel hepatitis E virus-like particle. Xi Bao Yu Fen Zi Mian Yi Xue Za Zhi 22: 339-342, 2006 (In Chinese).

21. Xu M, Behloul N, Wen J, Zhang J and Meng J: Role of asparagine at position 562 in dimerization and immunogenicity of the hepatitis E virus capsid protein. Infect Genet Evol 37: 99-107, 2016.

22. Ito K, Qin Y, Guarnieri M, Garcia T, Kwei K, Mizokami M, Zhang J, Li J, Wands JR and Tong S: Impairment of hepatitis B virus virion secretion by single-amino-acid substitutions in the small envelope protein and rescue by a novel glycosylation site. J Virol 84: 12850-12861, 2010. 
23. Hawkins P, Prescott MJ, Carbone L, Dennison N, Johnson C Makowska IJ, Marquardt N, Readman G, Weary DM and Golledge HD: A Good Death? Report of the second Newcastle meeting on laboratory animal euthanasia. Animals (Basel) 6: 50, 2016.

24. Zhang H, Dai X, Shan X and Meng J: Characterization of antigenic epitopes of the ORF2 protein from hepatitis E virus genotype 4. Virus Res 142: 140-143, 2009.

25. Meng J, Dubreuil P and Pillot J: A new PCR-based seroneutralization assay in cell culture for diagnosis of hepatitis E. J Clin Microbiol 35: 1373-1377, 1997.

26. Emerson SU, Clemente-Casares P, Moiduddin N, Arankalle VA, Torian U and Purcell RH: Putative neutralization epitopes and broad cross-genotype neutralization of Hepatitis E virus confirmed by a quantitative cell-culture assay. J Gen Virol 87: 697-704, 2006.

27. Fiedler K and Simons K: The role of N-glycans in the secretory pathway. Cell 81: 309-312, 1995.

28. Zhou YH, Purcell RH and Emerson SU: An ELISA for putative neutralizing antibodies to hepatitis $\mathrm{E}$ virus detects antibodies to genotypes 1, 2, 3, and 4. Vaccine 22: 2578-2585, 2004.

29. Meng J, Dai X, Chang JC, Lopareva E, Pillot J, Fields HA and Khudyakov YE: Identification and characterization of the neutralization epitope(s) of the hepatitis E virus. Virology 288 : 203-211, 2001.

30. Purcell RH, Nguyen H, Shapiro M, Engle RE, Govindarajan S, Blackwelder WC, Wong DC, Prieels JP and Emerson SU: Pre-clinical immunogenicity and efficacy trial of a recombinant hepatitis E vaccine. Vaccine 21: 2607-2615, 2003.

31. Li SW, Zhao Q, Wu T, Chen S, Zhang J and Xia NS: The development of a recombinant hepatitis $E$ vaccine HEV 239. Hum Vaccin Immunother 11: 908-914, 2015

32. Zhu FC, Zhang J, Zhang XF, Zhou C, Wang ZZ, Huang SJ, Wang H, Yang CL, Jiang HM, Cai JP, et al: Efficacy and safety of a recombinant hepatitis $\mathrm{E}$ vaccine in healthy adults: $\mathrm{A}$ large-scale, randomised, double-blind placebo-controlled, phase 3 trial. Lancet 376: 895-902, 2010.
33. Gurramkonda C, Adnan A, Gäbel T, Lünsdorf H, Ross A, Nemani SK, Swaminathan S, Khanna N and Rinas U: Simple high-cell density fed-batch technique for high-level recombinant protein production with Pichia pastoris: Application to intracellular production of hepatitis B surface antigen. Microb Cell Fact 8: 13, 2009.

34. Lorenzo FR, Tanaka T, Takahashi H, Ichiyama K, Hoshino Y, Yamada K, Inoue J, Takahashi $\mathrm{M}$ and Okamoto H: Mutational events during the primary propagation and consecutive passages of hepatitis E virus strain JE03-1760F in cell culture. Virus Res 137: 86-96, 2008.

35. Okamoto H: Hepatitis E virus cell culture models. Virus Res 161: 65-77, 2011

36. Yamamoto H, Suzuki J, Matsuda A, Ishida T, Ami Y, Suzaki Y, Adachi I, Wakita T, Takeda N and Li TC: Hepatitis E virus outbreak in monkey facility, Japan. Emerg Infect Dis 18: 2032-2034, 2012.

37. Takahashi K, Kitajima N, Abe N and Mishiro S: Complete or near-complete nucleotide sequences of hepatitis $\mathrm{E}$ virus genome recovered from a wild boar, a deer, and four patients who ate the deer. Virology 330: 501-505, 2004.

38. Li S, Tang X, Seetharaman J, Yang C, Gu Y, Zhang J, Du H, Shih JW, Hew CL, Sivaraman J and Xia N: Dimerization of hepatitis E virus capsid protein E2s domain is essential for virus-host interaction. PLoS Pathog 5: e1000537, 2009.

39. Jameel S, Zafrullah M, Ozdener MH and Panda SK: Expression in animal cells and characterization of the hepatitis E virus structural proteins. J Virol 70: 207-216, 1996.

(i) () $\odot$ This work is licensed under a Creative Commons CY AC Attribution-NonCommercial-NoDerivatives 4.0 International (CC BY-NC-ND 4.0) License. 